\title{
"I will not cut, even for the stone": origins of urology in the hippocratic collection
}

\author{
E. Poulakou-Rebelakou', A. Rempelakos², C. Tsiamis ${ }^{3}$, C. Dimopoulos ${ }^{4}$
}

${ }^{1}$ Department of History of Medicine, Athens University Medical School, Athens, Greece; ${ }^{2}$ Urological Department, Hippocrateion Hospital, Athens, Greece; ${ }^{3}$ Department of Microbiology, Athens University Medical School, Athens, Greece; ${ }^{4}$ National Committee of Ethics and Deontology, Athens, Greece

\section{ABSTRACT}

The Hippocratic Collection, including the most of ancient Greek medicine, remains still interesting, despite the recent advances that transformed definitely the urological healing methods. Considering the patient as a unique psycho-somatic entity and avoiding high risk surgical manipulations were the leading principles dictating the everyday practice. Contemporary physicians can still learn from the clinical observations in times of complete absence of laboratory or imaging aid, from the prognostic thoughts, the ethics, and the philosophical concepts, represented by the Hippocratic writings, tracing into them the roots of Rational Medicine in general and Urology in particular.

\section{ARTICLE INFO}

\section{Key words:}

Hippocratic Medicine; Renal

stone; Urology; Uroscopy

Int Braz J Urol. 2015; 41: 26-9

Submitted for publication:

December 17, 2014

Accepted after revision:

December 24, 2014

\section{INTRODUCTION}

I will not cut, even for the stone, but I will leave such procedures to the practitioners of that craft (1).

The roots of a rational approach to medicine, particularly to that of the objective observation by the bedside of the patient, are attributed to Hippocrates, a member of a family of well-known physicians on the island of Kos (2) (Figure-1). He lived and flourished in a very particular period in classical Greece, the golden age of Pericles ( $5^{\text {th }}$ century), when many dominant personalities made too many significant contributions to Western civilization (3). Among the scientific achie- vements of this period, the Hippocratic medicine developed the main concepts of the medical specialties. Some topics in Urology, such as uroscopy and stone disease, are presented here. The main references derived from the famous Hippocratic treatise entitled Aphorisms, an anthology of seven sections containing medical truths included in one or two phrases, like epigrams.

The most important healing methods are surgery (including the use of knife, lancet, and cautery), blood-letting, baths, drugs, ointments and plasters, fomentations and control of lifestyle (diet and exercise). There were no reliable anesthetics and antiseptic agents, making a surgical operation quite adventurous and painful, while 
Figure 1 - The famous plane tree in the island of Kos, native place of Hippocrates, under which the great physician of classical era teached young medical students (Engraving by Comte de Choiseul-Gouffier, Voyage pittoresque de la Gréce, 1782).

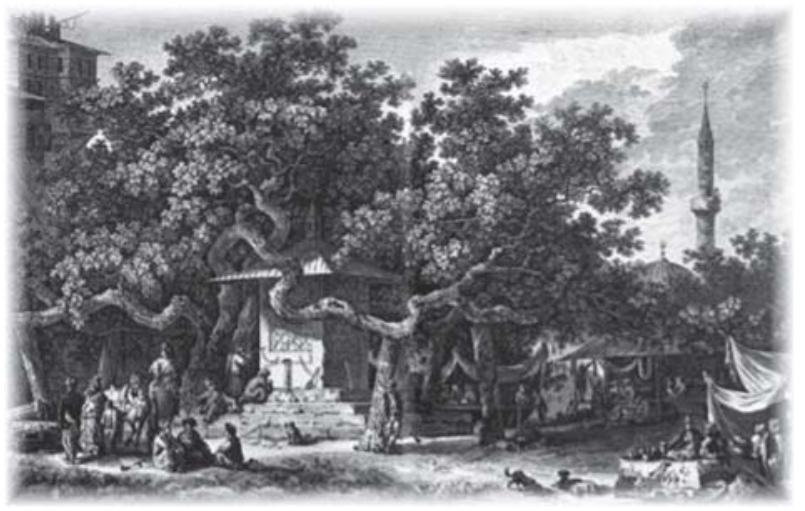

physicians and patients agreed on the avoidance of this procedure. Historians often comment that Hippocratic medicine delayed the development of Urology by condemning the cutting of the bladder for a stone's excision, but only the inexperience was condemned. On the contrary, the performance by the specialists was favored pre-announcing the future urological surgeons (4).

This paper intends to present the contributions of the Hippocratic writings to two main branches of the urologic specialty: the uroscopy (macroscopic urine observation) and the theory of the renal stone formation, both based on the study of the original Greek text.

Urological contributions of the hippocratic collection

A detailed study of Corpus Hippocraticum reveals several disorders of the urinary tract (5). The observations concerning the anatomy and physiology of the related organs and the etiology and treatment of various urological diseases seem accurate. Furthermore, the theory of stone formation is still valid and the diagnostic interpretations of the macroscopic urine examination (uroscopy) are still respectful (6). It is emphasized that no other system or organ of the human body gives us so much diagnostic or prognostic information by its excretion as does the urinary tract:
The urine must be observed to see how far it resembles that passed in health. The less it resembles healthy urine, the more diseased it is; the more it resembles it, the healthier it is. (Aphorisms VII, 67). The analysis of the urinary system in those times, where anatomic dissections were not allowed was rare and coincidental. The holistic approach combining information clinical observations from all organs added to the urologic experience and concluded to interpretations accepted until today. Moreover, the reluctance of undertaking cutting of the stone by cystotomy seems as evidence of evaluating the dangers and preserving the principle primum non nocere (Epidemics I, 11). Hippocrates considered that the physician must have two special principles in mind, namely, to do good or to do not harm.

Some operations on the kidney were not avoided; pyonephrosis and renal abscess were considered as operable cases and drainage by deep loin incision was recommended. For many centuries, cystotomy tended to cause severe disability and even death. Some complications were also reported such as the leakage of urine, common also after incisions on other organs (bowel). The most severe complication of cystotomy seemed to be gangrene and necrosis of the testis, due to the cut of the spermatic cord (2). The Hippocratic advice to the physicians was to avoid this procedure if possible, introducing the category of high risk operation, only for specialists, and attempting to protect the patients from untrained healers. Herodotus mentioned some specialists he met during his visit to Egypt: doctors for eyes, teeth, the abdomen and for obscure internal diseases (7).

One of the most typical examples refers to the need for differentiating the upper from the lower urinary tract infection: (8) Small fleshy objects, the shape of hairs, in the urine which is thi$\mathrm{ck}$, mean there is a discharge from the kidneys (Aphorisms IV, 76) and When blood clots in the urine are accompanied by strangury, abdominal and perineal pain, it is the parts about the bladder which are affected (Aphorisms IV, 80). The astuteness of the objective clinical observations in times of deteriorated anatomic knowledge is impressive (9). Most of the anatomic passages of the Corpus seem to have been based on animal dissection or 
secret human dissection (3). It is noteworthy that Hippocrates baptized many of the urological terms and diseases, such as lithiasis (=stone disease), cystitis, cystotomy, nephritis, orchitis, strangury and many others. However, it was possible to recognize the kidney and the bladder dysfunction and their clinical manifestations in disease.

\section{The theory of renal stone formation}

The Hippocratic concept of renal and bladder stone formation were based on detailed clinical observation and uroscopy (7). The possible ways of genesis of lithos (Greek word for stone) are described in several treatises of the Corpus.

The presence of a sandy sediment or of stones in the urine means that originally tumors grew in relation to the aorta and suppurated. Then stones were squeezed out through the blood-vessels together with urine into the bladder (On the Nature of Man, 14).

In one of the treatises attributed directly to Hippocrates (10) On Airs, Waters, and Places, a hygiene-oriented epidemiologic text, the qualities of water were considered responsible for stone formation. Drinking water collected from many different sources may be dangerous for stone disease, gravel and strangury:

When two sorts of water are mixed they quarrel with one another and will leave sediment of sand and it is by drinking this that the diseases mentioned above are cause.

The Hippocratic text offers more clinical observations:

If the neck of the bladder becomes inflamed and does not allow the urine to pass the densest and cloudiest part of urine is gathered together. The gravel formed coalesces to form a stone, preventing the urine from being passed. Great pain is thus caused.

A special mention for stone disease in childhood is notable, as it was unusual to focus on pediatric problems and, furthermore, to distinguish male and female children urological problems, based on the anatomic differences of the urethra.

Female children are less liable to stone because the urethra is short and wide and the urine is passed easily in males it is not straight and it is narrow as well. Moreover, girls drink more than boys (On Airs, Waters, Places, 9).

The patient's age plays a main role in stone formation: Sedimentation after urination is more frequent in children. It is because they are warmer (Epidemics VI, part 3, 7) and sandy urinary sediment shows that a stone is forming in the bladder (Aphorisms IV, 79). For the treatment of lithiasis, fluid intake is recommended (wine mixed with abundant water) or stronger drugs: By giving a medication to a patient with a stone, they have propelled the stone into the urethra by the force of medication so that it has passed with the urine (On Diseases I, 8).

\section{Hippocratic uroscopy observations}

The contribution of the Corpus to the development of uroscopy is priceless and his work on this field of Urology reflects the function not exclusively of the urinary system but of the whole body. Hippocrates studied the acute diseases and the evolution of urine during the stages of chronic diseases and emphasized on the constant appearance of certain elements in the urine. Colorless urine is bad; it is especially common in those with disease of the brain (Aphorisms IV, 72). The short phrase indicates a reduced ability to concentrate the urine and may refer to chronic renal failure or to diabetes insipidus (the latter unknown in $5^{\text {th }}$ century BC).

The sudden appearance of blood in the urine indicates that a small renal vessel has burst (Aphorisms IV, 78). It may signify necrotizing renal papillitis due to ischemic necrosis.

Bubbles appearing on the surface of the urine indicate disease of the kidneys and a prolonged illness (Aphorisms VII, 34). It may refer to chronic inflammatory activity in the glomeruli and may be identified with the term chronic glomerulonephritis (11).

It is impossible in a short article like this to include all the urologic knowledge of the Hippocratic physicians, acquainted through long experience. However, the symptoms of bladder disease (ulcer, tumor, psoriasis, lithiasis and inflammation) are all recognized by the urine appearance and the changes of this appearance. In the Aphorisms Hippocrates sums up much of what is of relevance to 
Urology. In fact, of the total 420 aphorisms, about 30 belong to the urologic specialty. With a general conclusion, the high incidence of urologic diseases in the prolonged age is clearly shown: Diseases of the kidneys and of the bladder are difficult to cure in the aged (Aphorisms VI, 6).

\section{CONCLUSIONS}

The most valuable contribution of ancient Greek medicine represented by the Corpus Hippocraticum to urology constitutes of the uroscopy diagnostic results and the theory of stone formation, as well as of the exact knowledge of cutting the stone by non-specialists. On the other hand, as an antidote to overconcentration of technology, the Hippocratic medicine offers its humanistic principles (ethics and deontology, health professionals by the patient's bedside) concerning the disturbances of the psycho-somatic world and placing the guidelines for the appropriate and early treatment of the diseases of the urological system. The Father of Rational Medicine predicted the necessity for specialized physicians with certain surgical abilities and broad medical knowledge, establishing in some way the specialty of Urology. Today's urologists can still learn from the prognostic thoughts, the ethical principles, the philosophic concepts and the humane messages of Hippocrates.

\section{CONFLICT OF INTEREST}

None declared.

\section{REFERENCES}

1. All the Hippocratic passages are deriving from the translation of Hippocrates by Loeb Classical Library (vol. I-VIII). Cambridge, MA: Harvard University Press, 1923-1995.

2. Chandwick J and Mann WN: The Oath. In: Lloyd GER (ed.), Hippocratic Writings. London, Penguin Books. 1983; pp. 67.

3. Sigerist HE. A History of Medicine. Early Greek, Hindu, and Persian Medicine. New York, NY-Oxford, Oxford University Press. 1961; pp. 261-2.

4. Edelstein L: Ancient medicine. Baltimore, MD, Johns Hopkins University Press. 1967; pp. 133-44.

5. Dimopoulos C, Gialas A, Likourinas M, Androutsos G, Kostakopoulos A. Hippocrates: founder and pioneer of urology. Br J Urol. 1980;52:73-4.

6. Murphy LJT. History of Urology. Springfield, IL, C. Thomas, 1972; vol. I, pp. 20-2.

7. Pollak K. Die Heilkunde der Antike. Griechenland-RomByzanz. Die Medizin in Bibel und Talmud. Düsseldorf und Wien, Econ Verlag Gmb. 1969. Greek translation. Athens, Papadimas DN. 2005; pp. 427-8.

8. Grene D. Herodotus History. Chicago \& London, University of Chicago Press. 1987; 2:82.

9. Marketos SG. Hippocratic medicine and nephrology. Am J Nephrol. 1994;14:264-9.

10. Eknoyan G. Origins of nephrology: Hippocrates, the father of clinical nephrology. Am J Nephrol. 1988;8:498-507.

11. Edelstein $L$. The genuine works of Hippocrates. Bull Inst Hist Med. 1939;7:236-48.

Correspondence address:

Effie Poulakou-Rebelakou, MD Department of History of Medicine Medical School, Athens University, Greece 51, Themidos St, Athens 15124, Greece Telephone: + 30697 788-8931 E-mail: efpoulrebel@med.uoa.gr 